\title{
O JOGO DE FUTEBOL NO CONTEXTO ESCOLAR E EXTRAESCOLAR: ENCONTRO, CONFRONTO E ATUALIZAÇÃO*
}

\author{
MS. GILBERTO LEANDRO BUSSO \\ Mestre em Educação Física pela UNICAMP \\ Professor do Ensino Básico em Hortolândia (São Paulo - Brasil) \\ e-mail: gilberto.busso@gmail.com
}

DR. JOCIMAR DAOLIO

Doutor em Educação Física pela UNICAMP e Professor Livre Docente do

Departamento de Educação Motora da Universidade Estadual de

Campinas (São Paulo - Brasil)

e-mail: jocimar@fef.unicamp.br

\begin{abstract}
RESUMO
Considerando que alunos aprendem em contextos extraescolares, o estudo objetivou compreender como o jogo de futebol de aulas de Educação Física está inserido em uma dinâmica de encontro, confronto e atualização com o jogo de futebol extraescolar. Foram observadas 22 aulas e 5 jogos extraescolares discentes; bem como foram realizadas 18 entrevistas com 12 alunos de duas turmas de $7^{a}$ e duas de $8^{a}$ séries do ensino público em Campinas, São Paulo. A análise constatou temas (Regras do jogo, Saber jogar e Jogo de meninas e meninos) que emergiram na dinâmica de encontro, confronto e atualização; e evidenciou suas implicações pedagógicas para a Escola, tendo em vista que a ação humana é importante para a mediação escolar de saberes do jogo de futebol no Brasil.
\end{abstract}

PALAVRAS-CHAVES: Educação Física escolar; mediação de saberes; futebol; cultura.

Estudo realizado com apoio financeiro do CNPq. 


\section{INTRODUÇÃO}

O jogo de futebol transita pelo contexto escolar e extraescolar no Brasil. Esta dinâmica pôde ser vivenciada no ano de 2005 em uma Escola pública de Campinas, São Paulo. Alunos gostavam de jogar futebol fora da Escola e queriam insistentemente jogá-lo nas aulas mesmo sem orientação docente, fato que requisitava a legitimação da atuação, pois a pluralidade planejada de conteúdos (Jogo, Dança, Esporte, Luta, Ginástica) não estava sendo compreendida na obtenção de fins considerados formais pela Escola, como a formação da cidadania. Assim, a vivência docente estava imersa em impasses pedagógicos, pois o que o planejamento propunha ensinar acerca deste jogo, principalmente em turmas de $7^{\mathrm{a}}$ e $8^{\mathrm{a}}$ séries, era algo que alunos não estavam dispostos a construir como saberes. Essa dinâmica e esses impasses exigiam estudo.

A literatura especializada apresentava algumas informações pertinentes para a problemática. Em primeiro lugar, seres humanos aprendem em família, na comunidade e outros universos sócioculturais em que saberes são construídos para além da Escola (BRANDÃO, 2002). Portanto, se alunos do ensino básico podem jogar futebol nestes contextos extraescolar e escolar, podem aprender neles. Segundo, como saberes escolares e extraescolares estão sempre em encontro, confronto (RODRIGUES JÚNIOR, 2008) e atualização (DAOLIO, 2002), a dinâmica estabelecida entre estes saberes evidencia a existência de semelhanças, diferenças e sugestão de algo novo proposto ao trabalho de alunos e Professores em aulas de Educação Física. Em terceiro lugar, a literatura ainda sugeria que o estudo a ser realizado deveria privilegiar o jogo de futebol a partir da perspectiva discente, e que a ação humana de alunos no jogo teria papel importante na dinâmica e nos impasses! .

Neste sentido, foi possível problematizar: a partir da perspectiva discente, como tal gostar relaciona-se com o querer, e como são construídos em relação ao jogo de futebol? Como são esses jogos discentes escolares e extraescolares para alunos? Como

I. Uma Professora de Educação Física entrevistada por Cruz de Oliveira (2006, p. 302) relata que a ênfase no futebol, presente nas aulas de todo o ano letivo, era justificada por uma "paixão dos alunos" e que eles reclamariam se não o praticassem. Segundo as palavras da docente: "Eles só querem saber de futebol". Podemos dizer que reclamar implica tomar uma posição contrária ao que está posto. Portanto, só querer saber de futebol representa, neste caso, só gostar de jogar o futebol que não é o escolar. Faria (2006) também argumenta que o futebol é o jogo que gera mais tensão educativa (ou impasses), o que dificulta a orientação docente nas aulas de Educação Física sobre o jogo. Um caminho direcionado pela literatura para se entender estes impasses sugeria a partilha de saberes. Schneider e Bueno (2005) indicam que é preciso considerar que o jogo de futebol é conteúdo escolar e extraescolar, isto é, comum, porque possui saberes que são compartilhados. Assim, os impasses referiam-se diretamente à partilha de saberes passível de ser compreendida em termos de semelhanças, diferenças e novidades entre o jogo na Escola e fora dela. 
funcionam as regras? Como alunos aprendem a jogá-lo? Como são esses jogos quando são realizados por meninas e meninos nestes contextos? Enfim, nossa problemática visou entender como assemelham-se e diferenciam-se saberes vistos como escolares e extraescolares, considerando que podem gerar algo novo ao planejamento escolar a ser trabalhado no período letivo. Apresentamos a nossa análise destas indagações com a esperança de que ela possa contribuir para a temática.

\section{UMA DÉMARCHE METODOLÓGICA SÓCIOCULTURAL}

A análise desta dinâmica de encontro, confronto e atualização fundamentou-se em um diálogo teórico-empírico estabelecido entre referenciais da Antropologia e da Educação Física com ações e explicações discentes apreendidas como processo e produto de formas sócioculturais familiares, comunitárias e escolares. Olhar, ouvir e escrever de pesquisador, propostos por Cardoso de Oliveira (2000), foram procedimentos realizados em observações e entrevistas com 12 alunos pertencentes a duas turmas de $7^{\mathrm{a}}$ e duas de $8^{\mathrm{a}}$ séries do ensino público de Campinas, São Paulo².

Entre Março e Setembro de 2008 foram observadas 22 aulas de Educação Física e realizadas 5 observações extraescolares ${ }^{3}$. Ambas as observações (escolares e extraescolares) totalizaram aproximadamente 72 horas $^{4}$. Foram também realizadas 23 entrevistas semiestruturadas (TRIVIÑOS, 1987), sendo 18 efetivadas com alunos (e as demais com a Diretora da Escola, Professora de Educação Física, pai

2. Alunos entre 13 e 14,5 anos foram escolhidos para a observação e as entrevistas porque suas ações revelaram saberes escolares e extraescolares do jogo de futebol em aulas de Educação Física; e porque aceitaram participar do estudo, mediante assinatura (própria e de pais/responsáveis) de um Termo de Consentimento Livre e Esclarecido acerca de questões éticas. A Escola e suas aulas de Educação Física foram escolhidas porque a Diretora e a Professora de Educação Física aceitaram participar do estudo; porque apresentaram Projeto Pedagógico e Plano de Ensino que sugeriam trabalho sistematizado com tal jogo; e porque, além disso, seus alunos também queriam e gostavam de jogá-lo insistentemente, fato captado por "espiadelas" realizadas em 2006, ano do primeiro contato com a referida instituição.

3. As observações extraescolares tiveram o objetivo de acompanhar esses alunos da Educação Física jogando futebol fora da Escola. Como as aulas aconteciam no mesmo local que esses alunos frequentavam aos finais de semana (Centro Comunitário), tivemos a oportunidade de acompanhar alguns(mas) desses(as) meninos(as) jogando aos finais de semana. Estas observações também possibilitaram um contato mais aproximado com pais, mães e/ou responsáveis legais por esses alunos. Infelizmente não dispomos de tempo nem espaço para uma exposição mais detalhada sobre estas observações. Para o entendimento de tal exposição, ver Busso (2009). Porém, estas informações extraescolares foram utilizadas na análise das informações que apresentamos aqui sinteticamente.

4. Observações escolares foram realizadas sempre em terças e quintas-feiras, no período da manhã, das 9h até I 3h, horário em que aconteceram as referidas aulas de Educação Física; e as observações extraescolares foram realizadas sempre aos finais de semana, frequentemente aos domingos no período da manhã (8h até I 2h) no Centro Comunitário. 
de aluna, Professor de Escolinha e Agente comunitário), em um total aproximado de 10 horas de gravação ${ }^{5}$.

As ações observadas e suas explicações verbalizadas constituíram-se em interpretações mantidas em um diário de campo, logo, podem ser entendidas como interpretações registradas na forma escrita para análise. $\bigcirc$ escrever de pesquisador adquiriu conotação especial, fundamentada no que Geertz (1973) denomina de inscrição: registro do que o pesquisador vê e ouve em campo, acerca do objeto que estuda, e que se transforma de um evento passado, que existe somente no momento de sua ocorrência, em uma descrição, que existe na inscrição, e pode ser (re) consultada6.

A inscrição, por sua vez, constituiu-se de interpretações discentes (e aquelas pertencentes a outros participantes do estudo) que foram interpretadas em diálogo com a teoria selecionada para a pesquisa: portanto, realizamos um empreendimento que envolveu a interpretação de interpretações (GEERTZ, 1973). Neste sentido, a interpretação foi entendida como aquilo que "[...] torna próprio o que, em princípio, era estranho; como apropriação" (RICOEUR, 1989, p. I56- I 58, grifos no original); "[...] um caso particular da compreensão [...] aplicada às expressões escritas [ou melhor, inscritas] da vida" (RICOEUR, 2000, p.85).

\section{UMA ESCOLA E SUAS AULAS DE EDUCAÇÃO FÍSICA: ORGANIZAÇÃO E OBJETIVOS}

A Escola em foco é uma construção sóciocultural. A ideia central de sua instalação em 1976 era a "possibilidade de que cada criança pudesse aprender algo para ser alguém", como afirmou o Agente comunitário em sua entrevista. Neste sentido, a comunidade atribui legitimidade a saberes escolares, pois estes viabilizam na contemporaneidade o difícil trânsito do trabalho bruto, do humano sem qualificações, para um trabalho de maior prestígio e rendimento seguro (BRANDÃO, 1990). Estes saberes são orientados por um Projeto Pedagógico (ESCOLA MUNICIPAL DE CAMPINAS, 2008a). Para a Diretora da Escola, o Projeto atende anseios da Prefeitura Municipal (instância governamental administrativa escolar) e anseios comunitários, e oferece

5. A condição de ter havido 18 entrevistas com 12 alunos se justifica pelo fato de que foi necessária uma segunda entrevista com alguns alunos, para que pudessem esclarecer e aprofundar alguns pontos que outros alunos conseguiram explorar em apenas uma entrevista. Como sabemos, essa condição é própria de pesquisas qualitativas. No caso da presente pesquisa qualitativa, estes esclarecimento e aprofundamento de informações visaram e possibilitaram-nos o alcance do objetivo proposto.

6. Geertz fundamenta a ideia de inscrição em Ricoeur ( $197 \mid$, p.53 |), especificamente na fixação pela inscrição: "[...] o que a inscrição fixa [...] é a significação do acontecimento da fala [e da ação] como evento, não o evento enquanto evento", por isso, há a possibilidade de constante consulta por parte do pesquisador. 
uma organização espacial-temporal-circunstancial das aulas de Educação Física que acontecem em um Centro Comunitário, devido às restrições espaciais escolares e mediante um acordo estabelecido entre Escola, comunidade e Prefeitura, denominado Comodato, que rege as normas de usufruto da Professora de Educação Física e seus alunos em período letivo. Esta condição reflete institucionalização, pois há reciprocidade estabelecida entre Escola, comunidade e Prefeitura. Instituições promovem um caráter típico das ações realizadas pelas partes, por seus atores, e que "[...] São acessíveis a todos os membros do grupo social particular em questão. [...] A instituição pressupõe que ações do tipo X serão executadas por atores do tipo X" (BERGER; LUCKMANN, 1985, p.79). Assim, Diretora, Professora e alunos desta instituição, e Agentes comunitários e governamentais têm finalidades mútuas quando se trata do ensino desta Escola: gestores escolar e governamental podem administrar; Comunidade auxilia as aulas mediante $o$ Comodato; Professores podem ensinar; e alunos aprender.

O principal objetivo do Projeto para as turmas de $5^{\mathrm{a}}$ a $8^{\mathrm{a}}$ séries da Unidade Escolar está expresso em propósitos educacionais:

Formar cidadãos, portadores de sólidas aquisições de saberes próprios do ensino fundamental, que Ihes auxiliem a interagir em seu meio social, agindo de forma sensível; pessoas que valorizam a cidadania e se posicionam contra desigualdades; aprofundar a sistematização de saberes a respeito de linguagens como a corporal como meio para produzir, expressar e comunicar suas ideias; construção de uma cultura de participação de alunos em jogos escolares, olimpíadas, campeonatos (ESCOLA MUNICIPAL DE CAMPINAS, 2008, p. I 5)․․

Neste sentido, institucionalizado, há a ideia (escolar-comunitária-governamental) da "formação de alguém-cidadão" - que inclui aulas de Educação Física e o jogo de futebol. Como o espaço-tempo-circunstância destas aulas é regido pelo Comodato, elas são apreendidas como contextuais, pois apresentam início, desenrolar e encerramento, e sequências, sistematizações e abordagens metodológicas escolares, pautados não apenas na dimensão física que é apreendida muitas vezes por si só, e em si mesma, como educativa.

Em meio às transgressões discentes das normas do Comodato e legitimações docentes para assegurar a pertinência, a consistência e o valor educativo do que é ensinado, estas aulas realizam-se fundamentadas em um Plano de Ensino (ESCOLA MUNICIPAL DE CAMPINAS, 2008b), que reflete a visão da Professora em relação a um projeto escolar elaborado para estes alunos. Como mencionou a Professora de Educação Física em sua entrevista: "Educação Física [escolar] é uma coisa que eu gosto. [...] Que eles consigam transferir o que vêem aqui para a vida

7. O referencial que sustenta este Projeto pauta-se em Leis, principalmente a LDB, Lei No 9.394/96 - que, por sua vez, tem fundamento na Constituição Brasileira de 1988. 
deles. [...] E que possam fazer da Educação Física uma profissão [... ] o meu projeto para eles é levar isso aqui para a vida". Se Professores constroem saberes sobre o ensino antes de construírem o processo de ensino (PENIN, 1994), este Plano reflete o envolvimento docente para com saberes a serem construídos por alunos nestas aulas, fazendo com que "dêem valor" ao ensino proposto na expectativa de "levarem algo para a vida" extraescolar futura (e) profissional.

O Plano de 2008 fundamenta-se principalmente no PCN e prevê como objetivos gerais e específicos para estas turmas:

Formação física básica; sociabilidade discente; usufruto refletido de fundamentos e regras; participação discente nas práticas escolares, sem discriminação por características pessoais, físicas e sexuais; repudiar qualquer tipo de violência nas práticas escolares; aprimorar condição física (força, resistência) e motora (agilidade); existência de gestos que indicam as regras do jogo; questionamento discente das regras do jogo escolar; e compreensão das práticas escolares (ESCOLA MUNICIPAL DE CAMPINAS, 2008b, p.7-8).

O futebol foi um conteúdo do $2^{\circ}$ bimestre em 2008 e o Plano de Ensino objetivou "trabalhar com Fundamentos do jogo (controle e domínio de bola com o peito do pé, com a parte interna e externa do pé); com Regras e gestos de arbitragem" (ESCOLA MUNICIPAL DE CAMPINAS, 2008b, p.9). É interessante notar a possível concatenação daquela ideia escolar-comunitária-governamental (formação de alguémcidadão) com a ideia destas aulas (alunos levarem algo para a vida extraescolar futura profissional). Esta concatenação sugere outra ideia mais ampla e profunda, vigente nesta instituição educacional, qual seja: a formação de alunos alguém-cidadãos na vida extraescolar futura (e) profissional ${ }^{8}$.

\section{DO JOGO COM E SEM REGRAS 9}

8. É importante salientar que cidadania é um tema contemporâneo recorrente. Além de estar inserido não apenas em Projetos Pedagógicos e em Leis brasileiras (como a Constituição Federal e a LDB), que visam e asseguram a formação de cidadãos brasileiros pela Escola, este tema é veiculado nas redes de sociabilidade nacional e internacional. Fala-se sobre cidadania em merchandising, em bares, em jogos de diversas modalidades, em alguma circunstância de desavença que deslegitime direitos legalmente assegurados, enfim, a cidadania está na "boca do povo", nas retóricas políticas, sociais e econômicas brasileiras, principalmente após o processo de redemocratização brasileira a partir da década de 1980 (MURILO DE CARVALHO, 2009).

9. Como sugerem estudiosos do tema Jogo, como Caillois (1986) e Huizinga (1999), não há jogo "sem" regras. Alunos também sabem disso, mas de outros modos. Por isso, o termo sem, em Itálico, expressa uma convicção discente que não pode ser apreendida como falsa ou verdadeira das interações às quais faz referência, mas como uma possibilidade dentre outras existentes, mantida neste estudo. Dito de outro modo, quando alunos dizem que o jogo é "sem" regras, esta interpretação discente possui algo muito significativo para o nosso estudo. Preservamos esse significado 
Ações discentes de interação na Escola e fora dela revelam que há acordos e saberes estabelecidos no início, desenrolar e encerramento de cada jogo. Há um "antes" deste início, para escolha de equipes na Escola e fora dela, que acontece por grupos de interesse (BRANDÃO, 2002) sustentado na amizade, em um universo relacional em que a interação desempenha um papel crítico na concepção e na dinâmica da organização social (DAMATTA, 1997). Deste modo, alunos jogam em casa, na rua, em condomínios, em clubes e na Escola com pessoas que consideram como amigas; há segregação escolar entre alunos na formação de "panelinhas" (união em grupo para mútuo auxílio no jogo em função da amizade); e a escolha representa saber como a pessoa joga, e isso é o que se sabe na interação. Esta condição reflete encontro com a sociabilidade do Plano de Educação Física, pois alunos usufruem de formas de interação na Escola e fora dela para a formação de equipes.

A organização e os modos de se fazer fora da Escola são considerados simples, ao passo que nela são "complexificados". Esta condição confronta-se com o Plano na medida em que este objetiva o usufruto refletido de fundamentos e regras. Formas não-ordenadas sobre modos de se fazer algo no futebol extraescolar representam uma condição diferente da escolar, em que o jogo é organizado em termos de um usufruto refletido de fundamentos e regras. A atualização é sugerida ao Plano, para que aulas lidem com características extraescolares de "simplicidade" no pensar e fazer, que orientam e influenciam início e desenrolar do jogo escolar.

Fora da Escola, há jogos "sem" regras e com aceitação discente de que "vale-tudo". Acordos são essenciais na solução de impasses no jogo, por isso, encontram-se com o Projeto da Escola na medida em que este prevê a sistematização de saberes e a interação discente com o meio social, na participação das práticas escolares mediante a expressão de ideias. Alunos apropriam-se de saberes escolares sistematizados sobre regras para configurar um jogo de futebol na Escola e para refletir sobre o jogo de fora dela, tendo em vista a marcação de faltas e penalidades, cobranças de linhas de fundo e lateral no jogo destes contextos: ou seja, há interação com expressão de ideias discentes nos acordos que alunos realizam. Estes acordos discentes ainda estabelecem semelhança com o Plano na medida em que está prevista a participação discente no jogo usufruindo das regras e a existência de gestos discentes que indiquem sua aceitação pelos alunos. Os gestos discentes observados evidenciam o usufruto e a aceitação delas.

Acordos e debates ainda demonstram a existência de saberes discentes sobre regras nas ações infratoras no jogo escolar e extraescolar. As infrações são nomeadas

primeiramente discente para compreendê-lo melhor, conforme veremos. 
por alunos como "cavalar", ação agressiva que expressa o "vale-tudo" extraescolar e está presente nas "caneladas, empurrões e chutes" do jogo escolar. ○ "cavalar" confronta-se com a interação com seu meio social, agindo de forma sensível proposto pelo Projeto da Escola. Mediante o "cavalar", meninos adquirem uma imagem representada na figura feroz, bruta e resistente, construção essa inspirada em um mamífero equídeo e indomável: "meninos são uns cavalos", como afirmam as alunas. Há ainda confronto do "cavalar" discente com o Plano de Educação Física na medida em que não há o questionamento discente das regras do jogo escolar previsto, pois alunos aceitam as regras deste jogo como leis a serem rigidamente seguidas; e na medida em que o Plano prevê repudiar violência nas práticas escolares, porém o "cavalar" é efetivado nas aulas, cujo nível de violência é inclusive permitido pela própria regra (ELIAS; DUNNING, 1985). A atualização sugerida ao Projeto e ao Plano neste caso refere-se às interações discentes que acontecem de forma nãosensível com seu meio social; na medida em que o "cavalar" discente desconfigura a interação de meninas e meninos, principalmente nos jogos das turmas de $8^{a}$ séries; e na medida em que alunos não-questionam regras escolares.

\section{SABER JOGAR}

O saber jogar é uma questão explorada no estudo tendo-se em vista que a ação humana é sempre simbolicamente mediada (RICOEUR, 1989). Tal ação tem sujeito, é construída e realiza-se em tempo-local-circunstância específico, possui referências contextuais; é sempre uma totalidade implicada na interatividade de suas partes; tem proposição que carrega mensagens em si que promovem efeitos; e constitui-se como forma de linguagem para interlocução, pois significados propostos estão entrelaçados com universos simbólicos que transcendem condições sociais de sua produção. Ações humanas perseguem intenções sociais de comunicação e compreensão (RICOEUR, I97I).

Compreendemos esta mediação simbólica no caso do giro por sobre a bola, realizado por alunos nas aulas observadas. Um giro discente por sobre a bola, construído fora da Escola e realizado por um garoto em aulas, era fruto de uma totalidade humana, constituída por fatores culturais, sociológicos, psicológicos e biológicos interativos; a mensagem que o giro propunha em si na aula era demonstrar uma aprendizagem extraescolar acerca do futebol, e tal mensagem produzia efeitos, pois enquanto esta ação era realizada, alguns alunos, meninas e meninos, sorriam, outros estavam cabisbaixos, outros andavam lentamente com as mãos na cintura em quadra, outros, sequer jogavam, alegando um não-gostar; e, se um giro por sobre a bola no jogo escolar é uma forma de linguagem que permite interlocução, possíveis interlocutores da ação encontram-se nas aulas. 
Estas características simbólicas sugerem que alunos aprendem e gostam de jogar futebol em casa, ruas, condomínios, clubes e na própria Escola, e estas vivências e compreensões ou aprendizagens (HOUAISS, 200 I) extraescolares fundamentamse na "simplicidade" do pensar e agir de modo a constituírem uma concepção de aprendizagem discente que pode ser aprofundada na Escola. Esta condição assemelha-se com o aprofundamento da sistematização de saberes a respeito das linguagens, dentre elas, a expressa nas ações humanas do Projeto da Escola. Para alunos, é isso o que acontece. Aqui, há um dos círculos sócioculturais em que o humano aprende a viver: a Escola. Para Brandão (2002), o aprender escolar está entrelaçado com características próprias em relação à educação extraescolar, pois há uma unidade sóciocultural de construção e transmissão de saberes por meio de tempo-espaço-circunstância, interações, conteúdos e metodologias pautadas em referenciais científicos (SOARES et tal, 1992) para a obtenção de fins considerados formais (formação da cidadania, por exemplo).

Alunos aprendem a girar por sobre a bola com familiares, assistindo televisão e/ou mediante navegação em websites (youtube, sobretudo) e/ou contato com amigos, e estes contextos discentes de aprendizagem revelam que o universo relacional de amizade aprofunda-se no aprender a jogar ao se sustentar em relações de parentesco. Há uma concepção discente em que o aprender está vinculado a jogar e gostar de jogar com amigos e parentes fora da Escola. Esta condição confronta-se com o Projeto e com o Plano na medida em que estes planejamentos não prevêem o gostar de jogar futebol como objetivo de trabalho - embora a docente goste de sua atuação. $\bigcirc$ gostar discente também confronta-se com o Plano na medida em que este prevê a formação física básica. $\bigcirc$ aprender discente sobre o futebol, na Escola e fora dela, relaciona-se com o gostar construído em interações sociais de amizades e parentesco, condição que ultrapassa a dimensão física humana estanque e isolada, pois está entrelaçada com dinâmicas sociais cujos significados mobilizam a totalidade humana discente no vivenciar e compreender algo do jogo. A atualização sugerida ao Projeto e ao Plano refere-se ao trabalho escolar com este gostar-aprender discente.

O que alunos aprendem na Escola e fora dela (driblar, dominar e passar a bola, fazer gol e jogar com regras) possibilita a construção de uma concepção sobre o saber jogar que é semelhante com o trabalho de controle e domínio de bola (com diferentes partes do pé, drible) e saber jogar com regras, considerado pela Escola muitas vezes como formas "corretas" de se fazer, segundo o Plano. Mas como na Escola há orientação docente, que define o "certo e errado", como explicam alunos, jogar fora dela implica "saber driblar, dominar, tocar ou passar a bola, fazer gol, jogar com regras do modo como se quer e se sabe”. Este saber 
jogar desses alunos vincula-se com o aprofundamento da concepção discente de aprendizagem (gostar-aprender), pois como alunos interagem socialmente com familiares, comunidade e escolares que lhes possibilitam a construção de um gostar de jogar, aprende-se a jogar porque gosta-se de jogar com amigos, familiares e colegas da comunidade e escolares. A partir do momento em que se aprendeu a jogar e sabe-se fazer algo no jogo, o que se quer fazer no jogo é precisamente o que se sabe. Há alunos que acreditam que gostam-aprendem-sabem-queremgiram/fazem; e alunos que não-gostam-não-aprendem-não-sabem-não-queremnão-giram/fazem. Deste modo, o que é construído na Escola é a segregação discente, sustentada em uma lógica de seleção de pessoas que sabem jogar e as que não-sabem jogar; que giram por sobre a bola e que não-giram por sobre a bola; e assim por diante.

Esta lógica de seleção confronta-se com o Projeto na medida em que este prevê a interação discente e a construção de uma cultura de participação de alunos em jogos escolares, olimpíadas, campeonatos, mas somente alguns alunos têm tal direito; e na medida em que ele utiliza a LDB como referencial, e ela prevê a valorização da experiência extraescolar, no entanto, somente experiências extraescolares de girar por sobre a bola são valorizadas por alunos e estas aulas. Demais alunos, que constroem outras formas de saber jogar que se encontram para além de giros, continuam segregados de tal cultura de participação. Tal lógica ainda confronta-se com o Plano na medida em que este prevê a participação discente nas práticas escolares sem a discriminação por características pessoais, físicas e sexuais, e o saber jogar de meninas é considerado por alunos de tal modo que permite a exclusão delas; e na medida em que dentre as obras de seu referencial o Plano utiliza o PCN, que prevê aulas mistas de Educação Física para convivência, tolerância, não-discriminação e compreensão mútua de meninas e meninos, mas ainda assim meninas de $7^{\mathrm{a}}$ e $8^{\mathrm{a}}$ séries são privadas da oportunidade de compartilhar aprendizagens com meninos de suas turmas no jogo de futebol.

A atualização sugerida ao Projeto situa-se em rever a consideração da ação discente como certa ou errada de forma que possibilite a participação de todos estes alunos em campeonatos e jogos escolares. A atualização sugerida ao Plano propõe interação de meninas e meninos em jogos mistos. Se a ação humana persegue intenções, as discentes são de expressão, revelação e proposição de ações e significados. Um giro por sobre a bola precisa ser compreendido por professores e alunos, que são interlocutores destes símbolos recorrentes, sobretudo na medida em que ações humanas como tal giro alteram acessos discentes no compartilhar aprendizagens e saberes deste jogo. 


\section{JOGO DE MENINAS E MENINOS}

O saber jogar discente gera tensão entre meninas e meninos em jogos de futebol mistos escolares e extraescolares. Tensão que evidenciada quando alunos (meninos e meninas) agem e explicam que um jogo de meninos é "rápido, veloz e forte", e um de meninas é "lento, devagar e fraco"; e estas características são vinculadas a modos de meninas e meninos fazerem como querem e sabem. Há semelhança com o Projeto da Escola na interação entre meninas e meninos, pois meninas e meninos atribuem às suas ações no jogo misto escolar e extraescolar uma explicação que é fruto de interação. Estas características ainda encontram-se com a condição física de força e condição motora de agilidade do Plano de Educação Física, pois "rapidez, velocidade e força, lentidão, vagareza e fraqueza" são características vistas como físicas, por alunos e pela professora.

A tensão é expressa na suposta desigualdade atribuída às diferenças destas pessoas no jogo. Jogar com meninas representa para meninos submeterem-se a uma condição de nível inferior em relação à "rapidez, velocidade e força" de seus jogos. Esta atribuição discente de não-ser igual entre si no saber jogar está sustentada em aprendizagens de meninas e meninos fora da Escola: enquanto meninos aprendem algo do futebol fora da Escola, meninas vivenciam e compreendem algo acerca de outras ações, extra-futebol, neste contexto. Diferenças dispostas em um plano horizontal tornam-se desigualdades inseridas em uma verticalidade hierarquizada, e esta condição confronta-se com o Projeto na medida em que este prevê interação entre meninas e meninos, mas diferentes aprendizagens extraescolares de meninos são decisivas para promover não-interação com meninas nas aulas; e na medida em que ele fundamenta-se na LDB, que prevê igualdade de condições para o acesso e permanência na Escola - portanto, no jogo escolar -, mas essa igualdade inexiste para meninas, consideradas hierarquicamente como desiguais. Há ainda diferença entre tais desigualdades e o proposto no Plano, em relação ao referencial PCN, que prevê aulas mistas que não acontecem devido à segregação de meninas do jogo de meninos: meninas das $8^{a}$ séries realizam aulas em dia e horário diferentes de meninos de suas turmas.

A atualização sugerida ao Projeto e ao Plano é sobre estas desigualdades: propõe um trabalho com esta não-interação de meninas e meninos no jogo, fruto de discriminação pessoal, física e sexual e do não-acesso e não-permanência de meninas no jogo de meninos. Esta desigualdade ainda é reforçada pelo "cavalar" de meninos, que supera sua condição primeira (interação discente com o meio social, agindo de forma não-sensível na Escola) para configurar-se profundamente como mecanismo social de meninos para não jogar com meninas, em que limites 
autorizados de violência permitidos pela regra favorecem a agressividade de meninos e, consequentemente, contribuem para a segregação entre eles e elas na aula. $\bigcirc$ "cavalar" acentua a tensão existente.

Esta tensão entre meninas e meninos em jogos escolares e extraescolares de futebol fundamenta-se em crenças sociais repletas de naturalidade e acessibilidade, em que temas (saber jogar) são apreendidos como inerentes a situações, intrínsecos a realidades; algo como as coisas são e funcionam assim - naturalidade e acessibilidade referem-se ao senso comum de grupos sociais (GEERTZ, 1983). Para alunos, a crença é de que "meninas não nasceram para jogar futebol" justamente porque são meninas, e jogar futebol é um tema inerente e intrinsecamente pertencente a círculos sócioculturais familiares, comunitários e escolares de meninos. Por isso, a crença é que "meninos nasceram para jogar futebol" porque as coisas são e funcionam socialmente assim. Nota-se que a hierarquia das desigualdades mencionada sustenta-se no contexto social mais amplo que o escolar. Para meninos, "futebol é coisa de homem"; para meninas "não!", porque "o futebol é coisa dos dois". A justificativa para ambos para isso é que ambos são melhores neste jogo, e o ser melhor é uma característica estritamente física (fazer dribles, gols; driblar, tocar a bola; fazer gol, saber chutar, driblar; e saber regras). Esta condição discente do tipo "futebol é coisa dos dois porque os dois são melhores" encontra-se com o Projeto na medida em que este prevê a interação de meninas e meninos em seu meio e o posicionamento contra desigualdades: meninas e meninos interagem na afirmação de que ambos são melhores no jogo de futebol dentro e fora da Escola. Tal condição ainda assemelha-se com o Plano na medida em que está prevista a formação física básica, e o saber jogar melhor de ambos é considerado por meninas e meninos como uma característica estritamente física, biológica, que estabelece afinidades com o saber jogar proposto em aulas.

Meninos consideram-se melhores porque são integrantes da categoria compreendida como homem, e assumem para si oportunidades de aprender algo do futebol em diversos contextos. Esta atribuição também é válida para meninas, principalmente as que aprendem e gostam do futebol - e que não são poucas -, mas contribui para reforçar a existência de um suposto universo masculino: como quem joga na Escola e fora dela é uma pessoa vista como machista/machudo/com um lado masculino, o futebol continua a pertencer a uma esfera reservadamente masculina (ELIAS; DUNNING, 1985). As crenças do senso comum ainda operam aqui. Às meninas são atribuídos papéis que convictamente estão vinculados a formas naturais, sustentadas no senso comum de funções fisiológicas (menstruação e gravidez) e psicológicas (sensibilidade e irracionalidade), bem como funções sociais (educação de filhos e trabalhos domésticos); enquanto meninos estariam próximos a formas 
sócioculturais (ORTNER, 1979), em relação ao jogo de futebol escolar e extraescolar. Deste modo, tal crença faz com que meninas sejam consideradas congenitamente como inferiores no jogar futebol - condição reforçada por meios de comunicação como a televisão, que veiculam e reproduzem a identidade brasileira supostamente masculina, que perpassa a totalidade humana de pessoas que se julgam pertencentes à categoria homem no querer-saber jogar futebol.

Esta condição de suposta inferioridade congênita atribuída a meninas confronta-se com o Projeto na medida em que este prevê interação entre meninas e meninos no jogo e o posicionamento contra desigualdades, mas há não-interação, pois meninas são situadas em um plano vertical hierárquico em relação a meninos no jogar futebol, e nem podem interagir de forma a posicionarem-se contra. Tal condição também confronta-se com a sociabilidade do Plano, pois meninas e meninos estabelecem não-sociabilidade no jogo; meninas são excluídas do jogo de meninos; e jogam separadas de meninos. Tal condição ainda confronta-se com a formação física básica deste Plano, pois a condição de inferioridade atribuída às meninas possui fundamentação social. A atualização sugerida ao Plano em relação a tal condição é possível porque ações e significados que constroem e reproduzem traços fortes de uma identidade masculina no jogo extraescolar estão ainda presentes nas aulas em tempos de inovação mundializada no futebol (valorização do futebol feminino, de seu saber jogar).

\section{DOS FINS: CONSIDERAÇÕES ACERCA DO JOGO DE FUTEBOL ESCOLAR E EXTRAESCOLAR}

Para atingir o fim que almeja, "formação de alunos alguém-cidadãos na vida extraescolar futura (e) profissional”, a Escola e suas aulas de Educação Física trabalham imersas nesta dinâmica de encontro, confronto e atualização de saberes escolares e extraescolares do jogo de futebol. Ao passo que alunos constituem-se como mediadores pedagógicos, pois universos extraescolares adentram aulas mediante ações discentes, este papel de mediação revela a própria dinâmica: quando alunos jogam fora da Escola "sem" regras, a base desta afirmação é menos a inexistência de regras no jogo do que a existência de regras escolares em jogos extraescolares; saber jogar representa saber agir em qualquer um destes jogos; e explicações discentes sobre estas ações sugerem que é preciso saber agir com meninas e meninos, e com regras nos jogos destes contextos.

Há uma dissociação entre o que é institucionalizado dentro e fora da Escola. Nosso campo de estudo em seu rico universo simbólico sugere que esta Escola 
constrói seus saberes pautada mais em referenciais científicos; fora dela, saberes pautam-se mais no senso comum. Como a ação discente carrega em si fins e características de saberes referenciados cientificamente e no senso comum, ela constitui-se como elo de saberes escolares e extraescolares. Algo como:

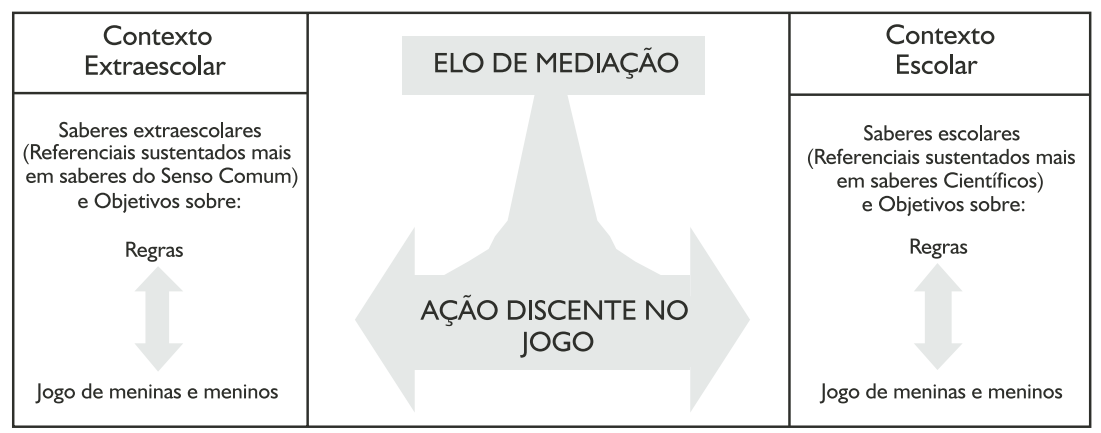

Elo de saberes escolares e extraescolares acerca do jogo de futebol

Saberes que adentram à Escola e que alunos "levam para fora dela", como sustentou a Professora de Educação Física, perpassam a ação humana, que é ainda o elo de mediação de saberes entre regras e o jogo de meninas e meninos em ambos os contextos. Os saberes sobre futebol possuem circulação, tanto penetram a Escola como a deixam, para adentrarem contextos extraescolares. Embora tenhamos focado nossa análise na possibilidade de saberes sobre futebol que adentra a Escola, é interessante notar que a ação humana no jogo como elo de mediação traz à tona a existência de um fluxo constante de saberes científicos e do senso comum sobre futebol na circulação. Portanto, considerar a ação humana como tal elo implica atribuir à Escola/Educação Física o compromisso social de lidar simultaneamente com esse fluxo, portanto lidar com saberes científicos e do senso comum construídos sobre esse jogo. As setas bidirecionais da ilustração indicam justamente a existência do fluxo. E o que o fluxo significa é a possibilidade de partilha existente entre estes saberes considerados mais escolares e mais extraescolares ${ }^{10}$.

Porém, tal fluxo revela uma nova dissociação. Como a ação discente carrega distintos saberes e intenções, ao passo que a Escola almeja a "formação de alunos alguém-cidadãos na vida extraescolar futura (e) profissional" por meio de saberes escolares do futebol, alunos querem como carreira profissional esse jogo. Isto significa

10. Outras implicações pedagógicas sobre a mediação de saberes no jogo de futebol nas aulas de Educação Física podem ser encontradas em Busso (20 I0). 
que querem seguir por um caminho cuja direção é distinta daquela acadêmico-escolar disposta em níveis sequenciais de ensino (básico, médio e superior). Esta dissociação conduz a uma outra. Para aprender a ser alguém no futebol é preciso conhecer alguém desta carreira, como sabem os próprios alunos. Como o imaginário do futebol no Brasil mobiliza multidões (DAOLIO, 2003), fazendo desta carreira o sonho de obter rendimentos seguros e bens materiais dos quais a maioria da população brasileira é privada (GIGLIO, 2007), a formação da cidadania pelo futebol problematiza-se. O ser alguém-cidadão no Brasil mediante esse jogo perpassa uma rede complexa de múltiplas esferas de ação e significação (família, comunidade, escola) que possui capacidade de construir uma posição intermediária em perspectiva de relação pessoal de amizade e institucional, sobrepostas, que se traduz em uma linguagem de negociação (DAMATTA, 1997). Há uma nação brasileira que opera fundada em cidadãos, desconhecidos (DAMATTA, I997; PEIRANO, 2006) - ou "ninguém" no futebol -; e uma sociedade brasileira funcionando por mediações institucionais. DaMatta (1997, p.75) afirma que esta é a "forma de cidadania às avessas [...]: reconhecida e definida por uma lei outorgada pelo Estado; e [...] ligada a um "sistema de estratificação ocupacional' e 'não a um código de valores políticos'”.

Esta rede extraescolar de múltiplas esferas de ação e significação, sustentadora de uma nação de brasileiros bem-sucedidos no futebol, adentra a Educação Física, "seduzindo" alunos à escolha desta carreira profissional, e fazendo com que haja representantes de uma nação brasileira e de uma sociedade brasileira. Há pessoas reconhecidas como alguém-cidadão no jogo; sabem agir e almejam esta carreira; giram por sobre a bola como profissionais; contribuem para fazer do jogo escolar uma área reservada; portam direitos e deveres, escolhem equipes, são escolhidos e requisitados, são privilegiados nas relações pessoais de jogos. Mas há pessoas com objetivos distintos, extra-futebol; seriam cidadãos-ninguém em relação ao jogo; realizam outras ações na Escola e fora dela; não portam direitos e deveres no jogar; são excluídos ou excluem-se de jogos; têm invadida a quadra em que jogam; são vítimas do "cavalar"; não jogam com as turmas; possuem relações de não-privilégio.

Portanto, o fim escolar torna-se problemático mediante o jogo de futebol. E a formação da cidadania pela Escola ainda perpassa outros conteúdos e outras disciplinas que também são dignas de análises. Atingir a formação da cidadania pelo futebol escolar implica estabelecer negociação com uma posição intermediária desta rede complexa de múltiplas esferas de ação e significação: a ação discente, o elo de mediação entre contextos e saberes escolares e extraescolares, pois, conforme sugerem as análises, o futebol profissional no Brasil perpassa caminhos extraescolares, então faz-se necessária a negociação. Se esta negociação pode não garantir que a 
cidadania e as aulas atinjam a todos no aprender, pelo menos ela reflete uma condição de interlocução no acesso às diferenças sócioculturais (objetivos distintos, modos de saber agir com regras e meninas e meninos) que poderiam ser consideradas, justificadas e legitimadas de outras formas em relação à exclusão, não-interação, desigualdade, discriminação e violência em jogos escolares... e extraescolares.

\section{The soccer game in context of school and of out-of-school: encounter, confrontation, and updating}

ABSTRACT: From the consideration that students learn out-of-school context, the study aimed to understand how the soccer game of Physical Education classes is inserted in a dynamic of encounter, confrontation, and updating, regarding the soccer game of out-ofschool. There were observed 22 classes, and 5 soccer games out-of-school of some students; as well as realized 18 interviews with 12 students belonging two classes of 7th and 8th grades of the public education in Campinas, São Paulo. The analysis found issues (Game rules, Know play, and Game of girls and boys) that emerged from dynamics of encounter, confrontation, and updating; and has evidenced its pedagogical implications for School, in order that the human action is important to scholar's mediation of knowledge of the soccer game in Brazil.

KEY WORDS: Physical Education at school; mediation of knowledge; soccer; culture.

\section{El juego del fútbol en lo contexto de la escuela y de fuera de flla: encuentro, enfrentamiento y actualización}

RESUMEN: Considerando que estudiantes aprenden en contextos fuera de la Escuela, el estudio tuvo el objetivo de comprender la forma como el juego de fútbol de clases de Educación Física se insertan en una dinámica de encuentro, enfrentamiento y actualización con el juego de fuera de la Escuela. Hemos hecho la observación de 22 lecciones, y 5 juegos de el estudiantes fuera de la Escuela; y 18 entrevistas con 12 estudiantes de dos grupos de 7 ' y de $8^{\circ}$ grado en una Escuela publica de Campinas, São Paulo. El análisis determinó temas (Reglas del juego, Aprender a jugar, y Juegos de niñas y niños) que surgió en la dinámica; y mostró sus implicaciones pedagógicas para la Escuela, mientras la ación humana es importante para la mediación escolar del conocimiento del juego del fútbol en Brasil.

PALABRAS CLAVE: Educación Física escolar; mediación del conocimiento; fútbol; cultura.

\section{REFERÊNCIAS}

BERGER, P.; LUCKMANN, T. A construção social da realidade. Petrópolis: Vozes, 1985.

BRANDÃO, C.R. O trabalho de saber. São Paulo: FTD, 1990.

A educação como cultura. Campinas: Mercado das Letras, 2002. 
BUSSO, G. L. O jogo de futebol no contexto escolar e extraescolar: encontro, confronto e atualização. 2009. I 62 f. Dissertação (Mestrado), Faculdade de Educação Física, UNICAMP, Campinas, 2009.

."Eu sou Filho do Ronaldinho!": uma noção de mediação de saberes na aula de Educação Física. In: DAOLIO, J. (Coord.). Educação Física escolar: olhares a partir da cultura. Campinas: Autores Associados, 2010.

CAILLOIS, R. Los juegos y los hombres. México: Fondo de Cultura Económica, 1986.

CARDOSO DE OLIVEIRA, R. O trabalho do antropólogo. 2. ed. São Paulo: Editora da UNESP, 2000 .

SOARES. Metodologia do ensino de educação fisica. São Paulo: Cortez, 1992.

CRUZDE OLIVEIRA, R. O futebol nas aulas de Educação Física: entre "dribles", preconceitos e desigualdades. Motriz, Rio Claro, v. I2, n.3, p.30I-306, set./dez., 2006.

DAMATTA, R. A casa e a rua. 5. ed. Rio de Janeiro: Rocco, 1997.

DAOLIO, J. A cultura da/na Educação Física. 2002. I I 2 f. Tese (Livre Docência), Faculdade de Educação Física, UNICAMP, Campinas, 2002.

. Cultura: Educação Física e futebol. 2. ed. Campinas: Editora da UNICAMP, 2003.

ELIAS, N.; DUNNING, E. A busca da excitação. Lisboa: Difel, 1985.

ESCOLA MUNICIPAL DE CAMPINAS. Projeto Pedagógico. Campinas, 2008a. 246p. Plano de Ensino da Educação Física. Campinas, 2008b. 25p.

FARIA, E. L. O futebol dentro e fora da escola: um estudo sobre as práticas de aprendizagem. In: REUNIÃO BRASILEIRA DE ANTROPOLOGIA, 25--Goiânia. Saberes e práticas antropológicas: desafios para o século XXI. Goiânia: UCG e UFG, 2006. v. I, p. I-20.

GEERTZ, C. The interpretation of cultures. New York: Basic Books, 1973. Local knowledge. New York: Basic Books, 1983.

GIGLIO, S. S. Futebol: mitos, ídolos e heróis. 2007. I60 f. Dissertação (Mestrado), Faculdade de Educação Física, UNICAMP, Campinas, 2007.

HOUAISS, A. Dicionário eletrônico Houaiss da língua portuguesa. São Paulo: Objetiva, 2001. HUIZINGA, J. Homo ludens. São Paulo: Perspectiva, 1999.

MURILO DE CARVALHO, J. Cidadania no Brasil: o longo caminho. I2. ed. Rio de Janeiro: Civilização Brasileira, 2009. 
ORTNER, S. Está a mulher para o homem assim como a natureza está para a cultura? In: ROSALDO, M.; LAMPHERE, L. (Org.). A mulher, a cultura e a sociedade. Rio de Janeiro: Paz e Terra, 1979.

PEIRANO, M. A teoria vivida. Rio de Janeiro: Jorge Zahar, 2006.

PENIN, S. A aula: espaço de conhecimento, lugar de cultura. Campinas: Papirus, 1994.

RICOEUR, P. The model of the text: meaningful action considered as a text. Social Research, New York, v. 38, n. 3, p.529-562, Autumn, 1971.

Do texto à ação. Portugal: RÉS-Editora, 1989.

Teoria da interpretação. Lisboa: Edições 70, 2000.

RODRIGUES JUNIOR, J.C. Os saberes cotidianos de alunos nas aulas de Educação Física: implicações para a prática pedagógica. 2008. 159 f. Dissertação (Mestrado), Faculdade de Educação Física, UNICAMP, Campinas, 2008.

SCHNEIDER, O.; BUENO, J.G.S. A relação dos alunos com os saberes compartilhados nas aulas de Educação Física. Revista Movimento, Porto Alegre, v. I I, n. I, p. 23-46, jan./ abr., 2005.

SOARES, C. et al. Metodologia do ensino de educação física. São Paulo: Cortez, 1992.

TRIVIÑOS, A. Introdução à pesquisa em ciências sociais. São Paulo: Atlas, 1987.

Recebido: 07 set. 2009

Aprovado: 12 fev. 201 I

Endereço para correspondência:

Gilberto Leandro Busso

Rua Dr. Hélcio Lizzardi, 424, - Parque Jambeiro

Campinas - SP

CEP: 13.042-430 